\title{
Revista

\section{Carência de dados e desafios metodológicos para o desenvolvimento dos estudos da indústria da música}

\author{
Lack of data and methodological challenges for the development \\ of studies of music industry \\ MicAel HeRSCHMANN \\ Professor do Programa de Pós-Graduação em Comunicação da Universidade Federal do Rio de Janeiro - UFRJ. \\ <micaelmh@globo.com>
}

\section{RESUMO}

Balanço das dificuldades metodológicas enfrentadas pelos pesquisadores que vêm trabalhando com a indústria da música no contexto atual marcado pela crise e reestruturação deste setor da produção cultural. Analisa-se aqui não só as implicações das carências de dados e dos indicadores culturais do setor musical para o desenvolvimento destes estudos, mas também se sublinha neste artigo a importância em se renovar os protocolos de investigação e de se desenvolver pesquisas que sejam capazes de gerar dados primários, visando com isso dar conta da complexidade da dinâmica da indústria da música do início do século XXI.

Palavras chave: Comunicação; Indústria da música; Metodologia.

\begin{abstract}
Balance of the methodological difficulties faced by researchers who have been working with the music industry in the current context marked by crisis and restructuring of this sector of cultural production. We examine here, not only the implications of the lack of data and indicators of cultural music industry for the development of these studies, but also underline the importance of renewing research protocols and developing researches that are able to generate primary data. Thereby aiming to account for the complexity of the dynamics of the music industry in the $21^{\text {st }}$ century.
\end{abstract}

KeYwords: Communication; Music industry; Methodology. 
Tos últimos anos, um número crescente de pesquisadores (oriundos de vários 1 campos disciplinares) tem se interessado em analisar não só o crescimento dos concertos e dos festivais independentes, mas também em avaliar o fortalecimento das "cenas" (Straw, 2006; Sá, 2011) e dos "circuitos" (Herschmann, 2010b) musicais regionais em diferentes localidades do globo. Como muitos estão cientes, já há alguns anos assistimos a um processo de transição da indústria da música mundial. Entre outras mudanças significativas na estrutura da sua cadeia produtiva poderíamos mencionar: que constatamos com grande perplexidade, por exemplo, a redução do cast de artistas e do quadro de funcionários das grandes empresas; a crise da noção de álbum que vai deixando de ser o objetivo central desta indústria ou a mercadoria mais valorizada nesta dinâmica de produção e consumo; o desaparecimento de antigas funções no setor e, ao mesmo tempo, o surgimento de novas profissões que empregam especialmente as novas tecnologias. Em função do ineditismo e da relevância destas mudanças, poder-se-ia dizer que a indústria da música, em certo sentido, constitui-se em uma espécie de laboratório para observar as transformações que já estão começando a afetar os diferentes setores das indústrias do setor cultural (Herschmann, 2010a, 2010b, 2011).

Analisando com atenção esta indústria, é possível identificar dois aspectos visíveis desta enorme avalanche de transformações que estão ocorrendo na indústria da música nos últimos anos: a) primeiramente, presenciamos não só a desvalorização vertiginosa dos fonogramas associada a vários suportes, mas também o crescente interesse e revalorização da música ao vivo especialmente nos centros urbanos; b) e, em segundo lugar, a busca incessante por novos negócios de sucesso, ou melhor, o crescente emprego das novas tecnologias e das redes sociais na web como una forma importante de reorganização do mercado, isto é, a utilização das tecnologias em rede como uma relevante estratégia de comunicação e circulação de conteúdos, de gerenciamento de 
carreiras artísticas, de formação e renovação de público e de construção de alianças com os consumidores (Herschmann, 2010a).

Em outras palavras, o que mais nos chama a atenção no contexto atual de crise da indústria da música, por um lado, é a perda de valor dos fonogramas gravados e comercializados em vários suportes e a pouca disposição dos consumidores em pagar por eles; por outro lado, constata-se a consolidação do setor de vendas dos fonogramas digitais e, ao mesmo tempo, um crescimento expressivo da música ao vivo em vários países. Na realidade, trabalho com duas hipóteses. Primeiramente, que a música ao vivo está se tornando o maior negócio da música hoje, em vários países. Poder-se-ia dizer que este negócio é muito relevante para as grandes empresas hoje com o agravamento da crise dos fonogramas (lembrando que no mundo independente os concertos ao vivo nunca deixaram de ser fundamentais). Em segundo lugar, que os fonogramas digitais devem em pouquíssimo tempo ultrapassar a venda em suportes físicos. Na realidade, o que vem ocorrendo (como podem ver nos gráficos apresentados, com dados da IFPI de 2011) é que a comercialização de fonogramas digitais tende a se estabilizar (mesmo as vendas através de celulares seguindo de modo geral estáveis) e as vendas em suportes físicos seguem caindo expressivamente.

Figura 1 - Vendas de música no mercado global (1997-2010). Fonte: IFPI, 2011.

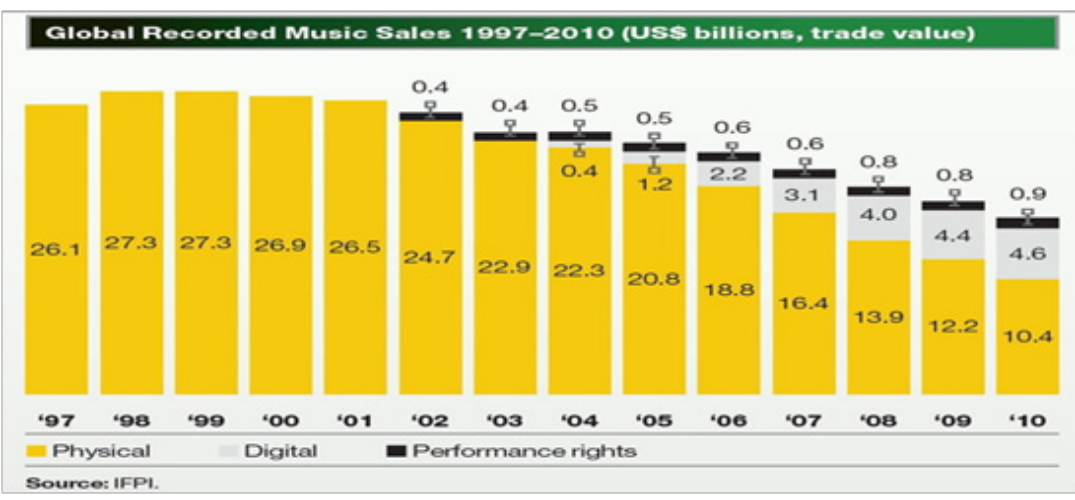


A pergunta que poderia se fazer é: a indústria da música estará reduzida daqui para frente a apenas a isso? Será que a indústria da música movimentou apenas 16 bilhões de dólares em 2010? Evidentemente, o que chama a atenção são os rendimentos indiretos gerados por esta indústria, os chamados produtos e serviços derivados deste setor (por exemplo, os rendimentos obtidos com a música ao vivo, videogames, venda de instrumentos musicais, etc.), que em 2010, segundo estimativas da IFPI (2011), movimentou cerca 132,3 bilhões de dólares (teve um crescimento de 4\% em relação ao ano anterior).

Ainda que possamos questionar se estas tendências vão se manter com a crise da economia mundial e com o intenso combate a pirataria, o que mais chama a atenção no quadro atual é a dificuldade de avaliar o que está realmente acontecendo porque não dispomos de dados públicos, especialmente quando examinamos para além das fronteiras da indústria fonográfica. Apesar da grande crise econômica já vir afetando a audiência dos concertos (inclusive, o relatório da IFPI de 2011 sugere um cenário menos promissor para a música ao vivo) a verdade é que não há grande interesse da indústria fonográfica em investir na mediação destes dados de forma sistemática (o que eles fazem é medir quanto rende por ano as 50 principais turnês de grandes ídolos internacionais). Evidentemente, há alguns dados isolados - como, por exemplo, nas estatísticas divulgadas pela mega empresa Live Nation, pelo site de entretenimento Pollstar, pela London School of Economics e pela prestigiosa International Federation of the Phonographic Industry (IFPI) -, mas os especialistas não dispõem de estudos regulares e historicamente extensos, que nos permita fazer qualquer afirmação de forma mais contundente ou abrangente ${ }^{1}$. É preciso lembrar que a música ao vivo sempre foi a área de atuação por excelência dos artistas, ou seja, o ganha pão, o negócio dos músicos. Portanto, talvez fosse interessante esta categoria profissional começar a pensar em gerar - a partir de suas associações nacionais - dados sobre concertos ao 
vivo. A questão é que se pudéssemos analisar a última década com mais estes dados estatísticos talvez tivéssemos uma leitura menos de crise da indústria e mais da sua transição, ou seja, poderia se perceber em que medida vem emergindo novas maneiras criativas de se ganhar a vida com a música.

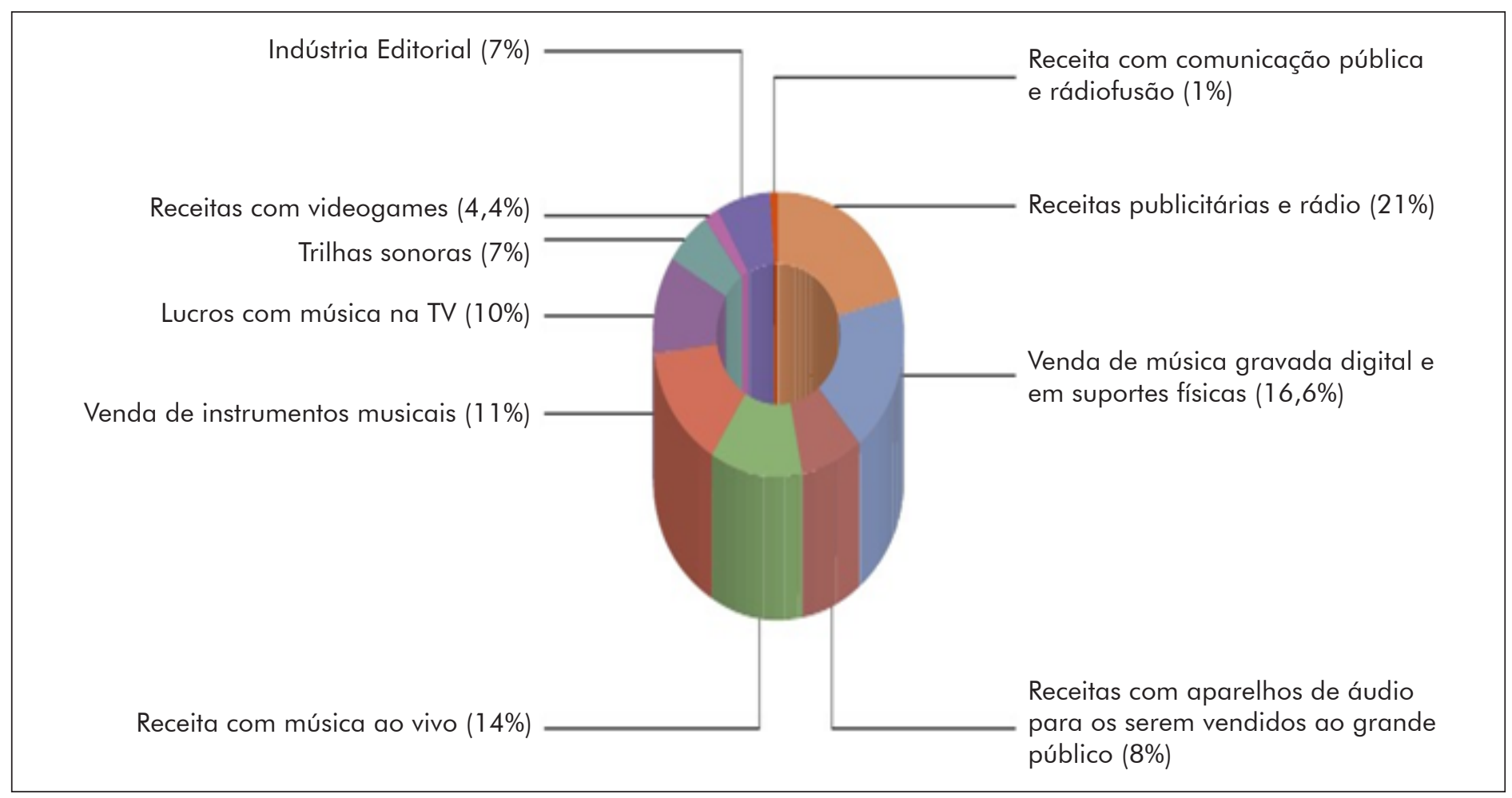

Figura 2 - Dados do mercado em 2009 Fonte: IFPI, 2011. 


\section{Necessidade de se gerar mais indicadores culturais (para além das fronteiras da indústria fonográfica).}

Poder-se-ia indagar: se não se dispõe de mais dados, como se pode sustentar a hipótese de que o negócio dos concertos ao vivo está se convertendo gradativamente no maior setor da indústria da música (não só da música independente)? É possível alicerçar este pressuposto nestes dados isolados da grande indústria, mas especialmente em algumas comprovações científicas oferecidas por pesquisas que envolvem um intenso trabalho de campo: não só naquelas que venho realizando no Brasil com vários circuitos da música, mas também nos vários resultados que são apresentados por vários pesquisadores como Yúdice (sobre os concertos na América Central), Ochoa (sobre os circuitos alternativos da Colômbia), Alfaro (sobre o huayno pop no Peru) e tantos outros que vêm sendo realizados de forma pioneira em diversas localidades do globo (Yúdice, 2007, 2011; Ochoa, 2001; Alfaro, 2009).

Evidentemente, a falta de dados não está relacionada apenas a um desinteresse da indústria fonográfica em aferir o negócio música ao vivo, mas também a dificuldade em realizar estas avaliações. Afinal, se por um lado hoje existem várias grandes empresas disputando o mercado de música ao vivo (por exemplo, na América do Sul, identificamse várias empresas atuantes que controlam o mercado de grandes festivais e concertos, tais como: Time For Fun do Brasil e Fênix y Pop Art da Argentina); por outro lado, existe um número enorme de pequenos concertos e eventos (como festivais indies) que são realizados de maneira informal - sem contratos e/ou notas fiscais de serviço -, como no caso, por exemplo: do tecnobrega, do funk carioca, do forró brasileiro, do huayno pop ou da cumbia villera (Herschmann, 2010b; Yúdice, 2011).

Vários pesquisadores comentam de forma bem-humorada que em alguns países se utiliza como recurso de investigação e de medição da música ao vivo uma espécie de billboard etílico, ou seja, se mede a demanda pelos concertos através do consumo 
de bebidas alcoólicas (Yúdice, 2011). Ou seja, muitas vezes mesmo o trabalho de campo é bastante complicado de ser executado, ou seja, não é simples fazer pesquisas censitárias de consumo cultural, pois os atores sociais não têm interesse em tornar esta informação pública, pois há uma clara preocupação com a questão da sonegação de impostos (Sunkel, 1999).

Em outras palavras, ainda temos muita dificuldade em compreender como funciona o mundo da música para além da indústria fonográfica, isto é, carecemos de indicadores culturais fundamentais: ainda dependemos do trabalho obstinado, na maioria das vezes desenvolvidos dentro de uma perspectiva sócio-antropológica, de alguns poucos pesquisadores (Yúdice, 2011). Claro que o cenário muda um pouco dependendo do país e do continente: evidentemente, alguns países conseguiram se organizar, através dos seus institutos de estatísticas nacionais, e elaboraram estudos de consumo cultural sobre o uso do tempo livre dedicado ao ócio. Claro que estes estudos são muito importantes e oferecem parâmetros fundamentais. Por outro lado, em muitos países (emergentes e/ou do Terceiro Mundo) sequer há um PIB da cultura, isto é, não há uma conta satélite separada da área cultural (Herschmann, 2007).

Se vários pesquisadores das indústrias culturais afirmam e reconhecem que a indústria da música está na vanguarda das transformações que estão acontecendo hoje e que afetarão as indústrias culturais nos próximos anos, é preciso também que questionemos os indicadores culturais disponíveis, que são disponibilizados a partir de medições construídas - por organismos que não são transparentes quanto a sua metodologia - e que geram análises que faziam mais sentido para medir a indústria da música do século XX, mas, certamente, não mais a atual. É preciso que se colabore na geração e renovação destas informações, que questionemos estes dados para que nossa pesquisa não fique refém de protocolos e informações viciadas. Poderia se afirmar que 
se "a indústria da música é um laboratório", este objeto de pesquisa exige investigações mais arrojadas (Herschmann, 2010b; Yúdice, 2011).

Pode parecer, mas não há nisso uma postura ingênua, irresponsável, romântica, libertária ou novidadeira: evidentemente há continuidades, ocorre com frequência a reprodução do capital e da estrutura de poder dentro desta indústria. Não se trata de negar isso. A grande indústria da música vem se reposicionando para atuar como intermediária da venda de música digital na internet - comprando os principais sites como o YouTube, MySpace ou Last.fm - ou mesmo como intermediária do mercado mundial dos concertos ao vivo. A Live Nation Entreteinment tem acordo com os principais artistas pop das majors e faz a intermediação dos shows mais rentáveis do mundo, envolvendo grupos como U2, Coldplay, Red Hot Chili Peppers, Metallica, etc. Evidentemente, nota-se também que os conglomerados transnacionais vêm buscando ter mais participação no mercado das apresentações ao vivo: inclusive, nos últimos anos, vêm obrigando seus artistas a assinarem novos contratos (chamados de 360 graus), nos quais têm maior participação da renda obtida pelos artistas com concertos ao vivo, direito de imagem e marketing (Herschmann, 2010b).

Apesar destas continuidades, é preciso entender também os novos negócios a partir das suas dinâmicas específicas e que, muitas vezes, não passam diretamente pelas majors. Por exemplo, não dá para compreender a dinâmica do circuito do samba e choro da Lapa (no Rio de Janeiro) ou do tecnobrega em Belém do Pará, no norte do Brasil, pelas articulações com as majors, ou com a tradicional indústria da música fonográfica. Nessas cenas está estruturada uma economia da cultura (que está para além das estatísticas disponíveis) que gera inclusão social, que cria - em cada um destes casos - milhares de empregos diretos e indiretos, movimentando o comércio local e promovendo a diversidade cultural local ${ }^{2}$. 
Assim, tendo em vista os desafios que são enfrentados hoje pelos investigadores, e especialmente a constatação da enorme carência de indicadores do negócio da música ao vivo, alguns pesquisadores começaram a se mobilizar para organizar projetos que gerem novos dados além dos oferecidos pela indústria fonográfica. Claro que é preciso contemplar os dados do negócio da música ao vivo das majors, que envolvem a organização de mega concertos e festivais como, por exemplo, o Rock in Rio, SWU, Lollapalooza e o Creamfields (todos realizados em vários continentes): esta é a parte mais visível deste negócio e pode ser que se consiga levantar estes dados com mais facilidade, pesquisando as principais empresas do mercado global.

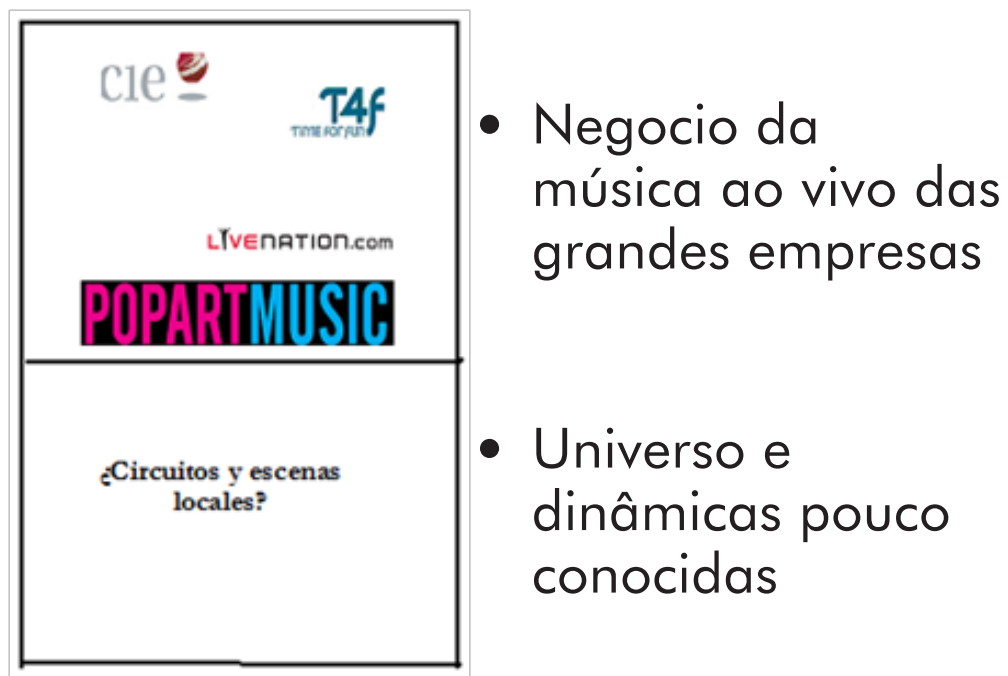

Figura 3 - Negócio da Música ao vivo

Fonte: elaboração própria 
Entretanto, é necessário o desenvolvimento de investigações que busquem mergulhar mais fundo no negócio da música ao vivo, estarão focadas especialmente em desenvolver um trabalho mais complexo, de geração de dados primários, ou seja: será preciso construir uma metodologia comum para coletar dados deste universo praticamente desconhecido, que não só é cada vez mais importante economicamente, mas também no qual estão emergindo novas formas de fazer negócios e cenas e circuitos de música local extremamente inovadores e criativos (Yúdice, 2011).

\section{Capacidade de mobilização da música ao vivo}

Apesar da estabilidade da comercialização dos fonogramas digitais, trabalho com a hipótese de que houve um deslocamento significativo das atividades mercantis: do consumo da música gravada para a música ao vivo. O grande interesse pela música ao vivo está relacionado ao alto valor agregado da experiência musical associada aos vetores da sociabilidade, da estética e da estesia. Ou seja, por um lado, a experiência de consumir fonogramas individualmente de forma não mercantil (através de trocas de arquivos) é largamente praticada e, por isso, os fonogramas vem perdendo rápida e significativamente valor comercial para os consumidores (indivíduos estão dispostos a pagar muito pouco ou nada por isso); e, por outro lado, a experiência coletiva ou social da música está cada vez mais valorizada: a música emerge hoje como élan social, uma espécie de paisagem sonora, que permite que os indivíduos vivenciem trocas, façam catarses, gerem memórias e identidades coletivas que são atualizadas nos eventos musicais. Os shows são não só um conjunto de produtos e serviços de alto valor agregado, mas também acontecimentos extremamente significativos para as vidas dos consumidores. Se entendermos isso, talvez venhamos a compreender porque os consumidores vão regularmente aos concertos, estão dispostos a fazer até movimentos de crowdfouding, 
bem como podem pagar bastante caro para ir ver o seu ídolo local, nacional ou internacional.

Cresce o número de pesquisadores que partem do pressuposto de que fora do âmbito do negócio das majors, envolvendo blockbusters ou o trabalho de astros pop de super vendas, a sustentabilidade dos artistas passa hoje pela sua capacidade de se inserir nas redes sociais, fazer parte de coletivos e de práticas de ativismo que se atualizam nas apresentações ao vivo, ou melhor, que tem no concerto seu momento de apoteose. Cada vez mais emerge uma espécie de economia mista, que tem como referência o capitalismo e a economia solidária e que envolve artistas, produtores independentes e fãs numa dinâmica colaborativa (Jenkins, 2006, 2008). Estes atores sociais desenvolvem práticas que contemplam: venda de entradas e promoções variadas, crowdfunding, participação em convocatórias de leis de incentivo a cultura, moedas para realização de escambo, entre outras estratégias e rotinas (Herschmann, 2010a).

A questão crucial hoje não é se pertence ao mundo do mainstream ou independente, pois as fronteiras entre estes dois universos são mais porosas do que parecem. $\mathrm{O}$ ponto é que estão emergindo novos negócios sustentáveis da música ao vivo, os quais promovem com algum êxito a música local. Estas cenas locais trazem um compromisso com a diversidade cultural em uma época marcada pela globalização, homogeneização cultural e forte penetração dos conglomerados transnacionais.

Poder-se-ia dar a título de exemplo os circuitos e cenas musicais que estão eclodindo em vários países da América Latina. Em trabalhos recentes, vários pesquisadores (tais como Yúdice, 2007; Alfaro, 2009; Autor, 2007; Ochoa, 2001) comentam o sucesso do huayno pop no Peru, do samba e choro no Brasil, e da cumbia villera, na Argentina ou Colômbia: é possível constatar que os atores sociais locais empregam esquemas de promoção através de fonogramas distribuídos, vendidos a valores muito baixos 
ou mesmo pirateados, aproximam-se muito da dinâmica - que é bastante exitosa e sustentável no Brasil - que encontramos no circuito do tecnobrega em Belém do Pará (Lemos, Castro, 2008), no circuito do forró de Fortaleza (Trotta, 2011), ou no funk tocado nas favelas e periferias do Rio de Janeiro (Sá, 2011). Ou seja, os fonogramas em suportes são utilizados para promover o epicentro do negócio que são os bailes, que mobilizam segmentos expressivos da população (no caso dos exemplos oferecidos, especialmente a mais pobre). Estes eventos, que são realizados regularmente nestas localidades, geram sustentabilidade a este território e crescimento de empregos expressivos, especialmente quando conseguem articular-se a outras atividades de gastronomia e entretenimento (Yúdice, 2004).

O caso do circuito do samba e choro da Lapa é um excelente exemplo, que ilustra a potência desta articulação. Principal vitrine de música ao vivo do país, a Lapa se tornou também um polo gastronômico e turístico da cidade. A experiência musical, presencial e coletiva é tão valorizada pelos consumidores que nesta localidade se ganha até dinheiro com fonogramas gravados em suportes físicos: vende-se muitos CDs, DVDs, mas também assessórios (tais como bottons e camisetas) ao final de cada concerto. Eles são importantes para os consumidores porque se tornam souvenirs da experiência coletiva/social da música considerada por eles memorável e prazerosa. Em 2009, dos 25 milhões de reais que foram gerados por mês na economia da cultura da Lapa, calculase que cerca de $1 / 3$ são provenientes da venda de entradas (para pagamento de couvert artístico) e de souvenirs, com relação aos concertos ao vivo (Herschmann, 2010b, 2007).

Evidentemente nem tudo é cor de rosa no chamado mundo independente. Os músicos são explorados, dentro destas estruturas, também pelos empresários locais que controlam as casas de concertos. Em inúmeras pesquisas são ressaltadas as tensões e desavenças com os empresários e produtores locais. Contudo, certamente nestes circuitos locais há mais espaço para a divulgação do trabalho deles, e, 
consequentemente, para a música local. Contudo, muitos músicos estão conquistando melhores condições financeiras atuando de forma mais polivalente, na condição de empresários e produtores. Eles afirmam que o grande capital deles é o reconhecimento da qualidade do seu trabalho por parte do público, que se traduz na capacidade destes artistas de conquistarem e mobilizarem "neotribos" (Maffesoli, 1987, 2007) de fãs e seguidores.

Cada vez mais eles percebem que precisam investir em organização e movimentos de associativismo, como os que caracterizam, por exemplo, a atuação de grande parte dos coletivos de rock no Brasil. Estes coletivos vêm se organizando em torno de grandes redes, tais como o Circuito Fora do Eixo, Rede Brasil de Festivais e Festivais Brasileiros Associados, as quais vêm realizando anualmente mais de 100 festivais no país inteiro e na América Latina. Só para que vocês tenham uma ideia da relevância destas redes de coletivos: utilizando estrategicamente novas tecnologias, redes sociais e processos da economia solidária, conseguiram mobilizar em 2012 cerca de 500 mil pessoas (especialmente na faixa etária de 16 a 30 anos) e movimentaram aproximadamente 80 milhões de reais (Herschmann, 2010b, 2011).

Claro que este crescimento da música ao vivo não deve ser considerado ingenuamente como a vitória dos empreendedores do universo independente. $\mathrm{Na}$ verdade, muitas vezes os conglomerados transnacionais sequer intervém junto a um nicho de mercado: a) muitas vezes as majors e a tradicional indústria fonográfica não têm interesse em entrar em certos mercados, isto é, não atuam porque são mercados muito pequenos ou porque os consumidores deste segmento têm pouco poder aquisitivo (isso acontece, por exemplo, com o funk carioca ou o huyano pop no Peru); b) outras vezes, os grandes conglomerados atuam de forma indireta nos nichos independentes, pois contam com pequenos selos e gravadoras (Albornoz, Gallego, 2011). 


\section{Considerações finais}

É importante que seja revisto com urgência a questão dos indicadores culturais, pois do contrário continuaremos reféns das formas de medição da própria grande indústria: dos dados divulgados pelas associações nacionais de produtores de discos, pela IFPI, e por empresas de consultoria que atuem no setor. Em outras palavras, é preciso realizar um esforço na geração de novos indicadores culturais que envolvam: associações de artistas, organismos ligados à sociedade civil organizada, observatórios das indústrias culturais, instituições de estatísticas associadas às organizações públicas.

Evidentemente, não se está afirmando que, nos últimos anos, muita pesquisa de altíssima qualidade não vem sendo realizada com os poucos indicadores do qual dispomos para analisar a indústria da música. Graças a estas investigações avançamos nos estudos sobre este importantíssimo setor da produção cultural.

Contudo, acredito que estes esforços de investigação seriam potencializados se dispuséssemos de dados mais amplos, para além da indústria fonográfica e de um debate viciado sobre pirataria, ou melhor, sobre os intercâmbios de fonogramas não autorizados pelo capital (que, em geral, fica refém de uma perspectiva monolítica e criminalizante dos organismos de direitos autorais). Parto do pressuposto de que a geração de novos indicadores permitirá realizar estudos e interpretações mais complexas da dinâmica do universo independente. A aposta é que alguns destes novos estudos subsidiarão a tão necessária renovação das políticas públicas, isto é, podem colaborar na elaboração de novas políticas que fomentem - de forma mais efetiva e de uma perspectiva endógena aos atores sociais de cada região - circuitos e cenas dedicados especialmente a produção local. 


\section{REFERÊNCIAS}

ALBORNOZ, Luis A.; GALLEGO, Juan Ignacio. Setor da música...independente? Apontamentos sobre a trama empresarial española. In: AUTOR. (org.). Nas bordas e fora do mainstream. São Paulo: Editora Estação das Letras e das Cores, 2011.

ALFARO, Santiago. Economía y cultura de la música andina. Lima: Tese (Doutorado em Sociologia) Departamento de Sociologia/PUC, 2009.

HERSCHMANN, Micael. (org.). Nas bordas e fora do mainstream. São Paulo: Editora Estação das Letras e das Cores, 2011.

. A indústria da música como laboratório. Observatório. São Paulo: Itaú Cultural, n. 9, 2010a, pp. 21-30. . Indústria da música em transição. São Paulo: Ed. Estação das Letras e das Cores, 2010b.

. Lapa: cidade da música. Rio de Janeiro: Mauad X, 2007.

International Federation of the Phonographic Industry (IFPI). Global Recording Industry in numbers - 2010. Londres: IFPI Market Publication, 2011.

JENKINS, Henry. Cultura da convergência. São Paulo: Aleph, 2008.

. Fans, bloggers and gamers. New York: New York University Press, 2006.

LEMOS, Ronaldo; CASTRO, Oona. Tecnobrega: o Pará reinventando o negócio da música. Rio de Janeiro: Aeroplano, 2008.

LONDON SCHOOL OF ECONOMICS. Music Sales. 2011. Disponível em: <www2.lse.ac.uk/home.aspx>. Acesso em: 12 jun. 2012.

MAFESOLI, Michel. O ritmo da vida. Rio de Janeiro: Record, 2007.

. O tempo das tribos. Rio de Janeiro: Forense-Universitária, 1987.

OCHOA, Ana M. G. Músicas Locales en Tiempos de Globalización. Buenos Aires: Norma, 2001.

POLLSTAR. New business of music. 2010. Disponível em: <www.pollstar.com>. Acesso em: 02 ago. 2010.

SÁ, Simone Pereira de. Cenas musicais, sensibilidades, afetos e cidades. In: GOMES, Itania; JANOTTI JUNIOR, Jeder (orgs.). Comunicação e Estudos Culturais. Salvador: EDUFBA, 2011.

SÁ, Simone Pereira; MIRANDA, Gabriela. Aspectos da economia musical popular no Brasil: o circuito do funk carioca. In: HERSCHMANN, Micael. (org.). Nas bordas e fora do mainstream. São Paulo: Editora Estação das Letras e das Cores, 2011. 
STRAW, Will. Scenes and sensibilities. E-Compós, n. 6, 2006. Disponível em: <www.compos.org.br/ecompos/ adm/documentos/ecompos06_agosto2006_willstraw.pdf>. Acesso em: 11 jun. 2012.

SUNKEL, Guillermo. (coord.). El consumo cultural en América Latina. Santafé de Bogotá: Convenio Andres Bello, 1999.

TROTTA, Felipe. O samba e suas fronteiras. Rio de Janeiro: Editora da UFRJ, 2011.

YÚDICE, George. A conveniência da cultura. Belo Horizonte: Ed. UFMG, 2004.

. Apontamentos sobre alguns dos novos negócios da música. In: Autor. (org.). Nas bordas e fora do mainstream. São Paulo: Editora Estação das Letras e das Cores, 2011.

. La transformación y diversificación de la industria de la música. In: BUSTAMANTE, Enrique (org.). La cooperación cultura-comunicación en iberoamérica. Madrid: Fundación Alternativas, 2007.

\section{NOTAS}

1 Alguns dados isolados publicados em revistas e sites especializados chamam significativamente a atenção nos últimos anos: a) a música ao vivo gerou 14\% da lucratividade gerada pelos distintos negócios que gravitam em torno da música (IFPI, 2010); a empresa Live Nation (que atua em 28 mercados em todo o globo) não só lucrou mais de 4 bilhões de dólares em 2010, mas projeta um crescimento anual de aproximadamente $15 \%$ para o próximos anos (IFPI, 2011); c) em 2010, a indústria de shows superou as vendas de fonogramas físicos na Inglaterra, tendo rentabilizado 1,36 bilhões de libras (e o mercado de música ao vivo local foi estimado em 1,54 bilhões de libras (London School of Economics, 2011); d) a música a vivo teve um crescimento estável de 10\% nos últimos três anos (Pollstar, 2010).

2 Para que se tenha uma ideia: por mês, o tecnobrega movimenta 14 milhões de reais (Lemos, Castro, 2008) e o circuito do samba-choro na Lapa, cerca de 25 milhões de reais (Herschmann, 2007). 